\title{
Control of Powdery Scab of Potato: Towards Integrated Disease Management
}

\author{
Richard E. Falloon
}

Published online: 5 September 2008

(C) Potato Association of America 2008

\begin{abstract}
Powdery scab of potato, caused by the plasmodiophorid pathogen Spongospora subterranea f. sp. subterranea, is an increasingly important disease where potatoes are grown in cool/temperate regions. Powdery scab lesions on tubers downgrade their quality as seed, fresh vegetable or processing potatoes, and the disease can severely harm crop productivity. Aspects of the biology of S. subterranea, including long-term persistence in soil, high and rapid reproductive potential, and, possibly, ability to infect alternative hosts, pose considerable problems for development of effective control of powdery scab. Methods shown to reduce the incidence and severity of the disease are reviewed. These include field choice and crop rotation, pathogen detection, use of resistant cultivars, planting disease- and pathogen-free seed tubers, appropriate pesticide treatments for seed tubers and/or infested soil, adjustment of soil nutrient status, and use of suitable management practices during crop growth. No single method is likely to give complete control of powdery scab, particularly where $S$. subterranea inoculum levels are high on seed tubers or in soil. Effective disease management will therefore depend on implementation of several appropriate methods, using an integrated approach to powdery scab control. This requires understanding of the biology of $S$. subterranea, and comprehensive and conscientious adherence to appropriate disease control methods during most stages of the potato crop management cycle.
\end{abstract}

The online version of the original article can be found at http://dx.doi. org/10.1007/s12230-008-9022-6.

R. E. Falloon $(\triangle)$

New Zealand Institute for Crop and Food Research Limited,

Private Bag 4704,

Christchurch, New Zealand

e-mail: falloonr@crop.cri.nz
Resumen La roña de la papa causada por el patógeno plasmodiofórico Spongospora subterránea f. sp. subterránea es una enfermedad crecientemente importante en regiones de clima frío donde se siembra papa. Las lesiones de roña en los tubérculos disminuyen la calidad de la semilla, la papa como hortaliza fresca o para procesamiento, y la enfermedad puede dañar severamente la productividad del cultivo. Aspectos de la biología de S. subterránea incluyendo su persistencia por largo tiempo en el suelo, potencial de gran y rápida reproducción y posiblemente, la habilidad de infectar huéspedes alternativo plantea considerables problemas para el desarrollo de medidas de control efectivas de la roña. Los métodos probados para reducir la incidencia y severidad de la enfermedad están siendo revisados. Estos incluyen la elección del lugar y rotación del cultivo, detección del patógeno, uso de cultivares resistentes, siembra de tubérculos semilla libres del patógeno, tratamiento adecuado de pesticidas para los tubérculos semilla y/o suelo infestado, ajuste del estado de nutrientes del suelo y uso de las prácticas de manejo convenientes durante el desarrollo del cultivo. Ningún método solo parece dar control completo donde los niveles de inóculo de $S$. subterránea son altos sobre los tubérculos semilla o en el suelo. El manejo efectivo de la enfermedad dependerá por lo tanto de la implementación de varios métodos apropiados, usando un enfoque integrado para su control. Esto requiere el conocimiento de la biología de $S$. subterránea y una completa y consciente adhesión a los métodos de control apropiados de la enfermedad durante la mayoría de las fases del ciclo de manejo del cultivo de papa.

The Resumen was inadvertently omitted from this article which was published in Vol. 85 No. 4, p. 253. It is reproduced here along with the English abstract.

Springer regrets the error. 